\title{
Utilização de recursos audiovisuais como estratégia de ensino de Microbiologia do Solo nos ensinos fundamental II e Médio
}

\section{Use of audiovisual resources as a teaching strategy for Soil Microbiology in primary and secondary education}

\author{
${ }^{1}$ Rogério Custódio Vilas Bôas rogeriovilas@gmail.com \\ ${ }^{2}$ Antonio Fernandes Nascimento Junior \\ ${ }^{3}$ Fatima Maria de Souza Moreira
}

\section{RESUMO}

O presente estudo buscou informações sobre uso de recursos audiovisuais (RA) pelos professores de Ciências e Biologia de uma escola pública no município de Lavras - MG, para subsidiar a produção de um vídeo. Este vídeo será usado como um organizador prévio para o ensino de Microbiologia do Solo no Ensino Fundamental e Médio. Este conteúdo é muito abstrato, fora do imaginário da maioria dos estudantes desses níveis de Ensino. Porém não pode ser negligenciado pelos professores e estudantes, para que percebam a importância dos micro-organismos do solo na sustentabilidade dos ecossistemas agrícolas e naturais. Os objetivos desse trabalho foram verificar com que frequência os professores e estudantes do $9^{\circ}$ ano do Ensino Fundamental II e $3^{\circ}$ ano Ensino Médio utilizam os RA como ferramenta na melhoria do aprendizado; identificar a preferencia dos estudantes entre os RA; verificar a frequência da utilização dos RA no Ensino de Ciências de Biologia e se professores e estudante concordam que o uso de vídeos/aulas poderia ajudar no ensino de Microbiologia do solo. A coleta de dados foi realizada através de questionários semiestruturados com perguntas objetivas e discursivas para os estudantes e professores. Após analise das respostas dos questionários, constatou-se que os professores não foram qualificados para utilizarem determinados recursos, e que os estudantes preferem aulas com uso de Datashow e acreditam que os R/A podem ajudar no ensino de Microbiologia do Solo. Os dados irão orientar a produção de uma vídeo/aula em Microbiologia do Solo para os estudantes.

Palavras-chave: Recursos audiovisuais. Microbiologia. Ferramenta de Ensino.

\begin{abstract}
The present study seek informations about the use of audiovisual resources (RA) by teachers of Science and Biology of a public school in Lavras city - MG., to subsidy the production of a video. This video will be used as previous organizer to the teaching of Soil Microbiology in the elementary and High schools. This content is abstract, outside the imagination of most students at these levels of education. But this content can not be overlooked by teachers and students, to realize the importance of soil microorganisms in the sustainability of agricultural and natural ecosystems.The objectives of this study were to assess how often teachers and students in the 9th year of Secondary School and 3rd year high school using the audio / visual resources as a tool to improve learning; identify the preference of the students between audiovisual resources; check how often audiovisual resources are used in the Teaching of Science and Biology and if teachers and students agree that the use of videos/lessons could help in teaching soil microbiology. Data collection was conducted through structured questionnaires with objective and opened questions for students and teachers. After analyzing the survey responses, it was found that teachers were not qualified to use certain resources, and that students prefer classes with the use of data projectors and believe that audiovisual resources can help in the teaching of Soil Microbiology. Data will guide the production of a video/class on Soil Microbiology for the students.
\end{abstract}

Keywords: Audiovisual resources. Microbiology. Tool of teaching.

1 Departamento de Biologia e Ciência do Solo; Área: ciência do solo, área de concentração em microbiologia e processos biológicos do solo. Ensino de microbiologia.

2 Professor e Doutor Departamento de Biologia - Laboratório de Ensino de Biologia.

3 Professora PhD. Departamento de Ciência do Solo DCS/UFLA; Pesquisadora do Laboratório de Microbiologia e Processos Biológicos do Solo. 


\section{INTRODUÇÃO}

A Microbiologia do Solo é um conteúdo que deve ser inserido nas disciplinas de Ciências do Ensino Fundamental II e de Biologia do Ensino Médio, devido à relevância ambiental e agrícola de vários processos realizados pelos micro-organismos do solo. Os conteúdos dessas disciplinas envolvem estruturas e processos complexos, que muitas vezes são difíceis de serem ensinados e aprendidos.

A exploração de recursos visuais no ensino de Biologia é intensa e, portanto, é comum encontrar modelos, tanto macro como microscópicos, para facilitar a compreensão desses conteúdos (LEHMAN, 1985).

Hoje tem sido cada vez mais comum o uso de recursos multimídias para representação de modelos biológicos o que tem criado diversas possibilidades educacionais (DEV; WALKER, 1999; PEAT; FERNANDEZ, 2000), mas deve-se tomar o cuidado de não se criar uma realidade paralela que exista apenas nas telas de TV e computadores, e que jamais poderá ser extrapolada à vivência dos estudantes e relacionada aos conteúdos apresentados nas aulas expositivas e livros didáticos.

O ensino de Biologia apresenta algumas dificuldades próprias, além das que compartilha com disciplinas afins. Em Biologia, os estudantes são expostos a um grande número de fenômenos que geram dificuldades na formação de uma visão geral e articulada.

A busca por ferramentas de ensino que possam deixar o processo de ensino-aprendizagem mais motivador tem sido uma das grandes dificuldades encontradas por parte dos professores de nível fundamental e médio (SOUZA; NASCIMENTO JUNIOR, 2005).

Quando o professor é ciente das dificuldades de determinados conteúdos, estes podem ser pelo menos amenizados por medidas metodológicas, incluindo aqui o uso dos recursos audiovisuais. A utilização de animações, por exemplo, tem grande vantagem sobre figuras convencionais, quando se trata de promover a compreensão de fenômenos essencialmente dinâmicos. Estão nesta categoria as transformações que necessitam de um grande número de figuras para completar o esquema pretendido, ou que consistam de eventos distintos, mas simultâneos. Existem diversos fenômenos biológicos, cujas compreensões poderiam ser facilitadas por animações e recursos audiovisuais.

No contexto da dificuldade do ensino de Ciências e Biologia, pretendemos produzir uma vídeo/aula para facilitar o ensino de Microbiologia do Solo, que de certa forma, contribuirá para uma melhor compreensão da Microbiologia ensinada no Ensino fundamental II e Médio, e também de vários processos ensinados em Ciências e Biologia. A partir de determinados ajustes feitos pelos professores de Ciências esta vídeo/aula poderá ser trabalhada também no Ensino Fundamental I.

Atendendo aos Parâmetros Curriculares Nacionais (PCN) (BRASIL, 2010) para o Ensino Médio, a produção desses multimeios baseia-se na ideia de que os modelos na ciência servem para explicar tanto aquilo que podemos observar diretamente, como aquilo que só podemos inferir.

Para promover um aprendizado ativo, especialmente em Microbiologia do Solo, que realmente transcenda a memorização de nomes, é importante que os conteúdos sejam apresentados de forma clara e contextualizados. As vídeo/aulas são recursos que facilitam principalmente o acesso a bancos de imagens, filmagens ilustrativas, descrições experimentais e esquemas animados, para descrever processos e características do ambiente ou de seres vivos, nos níveis micro e macroscópicos. Através da observação, animação e leitura de texto, os estudantes experimentam diferentes formas de obter as informações sobre os conteúdos. As animações, resoluções e discussões de questões apresentadas nas vídeo/aulas irão permitir aos estudantes relacionar fenômenos, fatos, processos e ideias dos conteúdos em Biologia, elaborando conceitos, identificando regularidades e diferenças, construindo generalizações, (GALEMBECK et al.,2004). 
Os vídeos estão diretamente ligados à televisão. Eles são meio de descanso e entretenimento para o telespectador. Atualmente muitos vídeos estão disponíveis na internet e podem ser assistidos através do monitor de um computador, assim como as animações que podem ser gravadas em um CD ou DVD para serem assistidas na televisão ou pelo Datashow.

Neste contexto, de que os vídeos são uma forma de entretenimento, para um estudante, assistir a um vídeo na escola não é apenas mais uma aula, mas sim uma forma de descanso, de sair da rotina do quadro e giz. O professor como mediador da formação do estudante, deve aproveitar dessa expectativa positiva do estudante e fazer o uso dos vídeos como mais uma estratégia de ensino (PINHO; LEPIENSKI, 2013).

Um dos objetivos da prática docente é a inserção das novas tecnologias no processo de ensino-aprendizagem da Biologia, especialmente no estudo dos conteúdos de forma prática. Para isso, o uso de vídeo e animações torna-se um importante recurso como estratégia de ensino (OLIVEIRA; JUNIOR, 2012).

Como toda ferramenta de Ensino, o uso de um filme ou de uma simulação multimídia deve ter uma função definida no plano de Ensino elaborado pelo professor para um conteúdo específico. A habilidade e capacitação técnica do professor aparecem na hora das escolhas do material instrucional e do ponto de inserção dentro do curso (ROSA, 2000).

Nessa perspectiva, o professor precisa estar atento para a constante reformulação e direcionamento da aprendizagem, deve buscar novas metodologias que contemplem os interesses dos estudantes, que diariamente tem contato com as novas tecnologias.

O presente trabalho teve como objetivos verificar com que frequência os professores e estudantes do $9^{\circ}$ ano do Ensino Fundamental II e $3^{\circ}$ ano Ensino Médio utilizam os RA como ferramenta na melhoria do aprendizado; identificar a preferencia dos estudantes entre os RA; verificar a frequência da utilização dos RA no Ensino de Ciências e de Biologia, e se professores e estudante concordam que o uso de vídeos/aulas poderia ajudar no ensino de Microbiologia do solo.

Os resultados desse trabalho irão subsidiar a produção de um vídeo sobre Microbiologia do Solo para a construção desse conhecimento. Procurando inovar, saindo do ensino tradicional (onde geralmente se utilizam apenas o livro didático, quadro e giz) e pensando no estudante que, cada dia, está mais ansioso em aprender coisas novas e diferentes.

\section{METODOLOGIA}

Para a coleta dos dados foram utilizados questionários semiestruturados, (ver no item apêndices), que é a junção de questões fechadas e abertas. Para Minayo (2004, p.108) o questionário semiestruturado "combina perguntas fechadas (ou estruturadas) e abertas, onde o entrevistado tem a possibilidade de discorrer o tema proposto, sem respostas ou condições prefixadas pelo pesquisador”.

. Os sujeitos de pesquisa foram 80 estudantes do $9^{\circ}$ ano do Ensino Fundamental II e 83 estudante do $3^{\circ}$ ano do ensino Médio do turno da manhã, e também quatro professores sendo dois de Ciências e dois de Biologia da Escola Estadual Cinira Carvalho, Lavras - MG. A escola oferece ensino a partir do $5^{\circ}$ ano do Ensino Fundamental I ao $3^{\circ}$ ano do Ensino Médio, com aproximadamente mil e duzentos estudantes. Possui 02 Datashows e 02 conjuntos de TV/DVD (móveis) que facilmente podem ser deslocados de um ambiente ao outro, conforme necessidades para fins didáticos. Conta ainda com um Laboratório de Informática com 25 computadores, nem todos com acesso à Internet (Lab. Info) e 01 Aparelho de Som portátil com rádio AM/FM e toca CD (Ap. de Som). 
O questionário dos estudantes indagava acerca da frequência de utilização dos recursos audiovisuais pelos professores em suas aulas e sobre a preferência dos estudantes por determinado recurso.

O questionário dos professores continha perguntas acerca dos supostos motivos que impossibilitariam a utilização de determinados recursos audiovisuais na escola; se recebiam capacitação para trabalharem com esses recursos; em que situações esses recursos eram usados; e qual recurso áudio/visual melhor contribuiria para ensino de Microbiologia Solo para estudantes do Ensino Fundamental II e Médio.

Antes da aplicação dos questionários, estudantes e professores foram convidados a participar da pesquisa, logo após, o questionário foi aplicado. Após análise das respostas dos questionários, os dados foram quantificados e apresentados sob a forma de gráficos. Estes dados serão levados em consideração para orientar a produção de uma vídeo/aula em Microbiologia do Solo para os estudantes do $9^{\circ}$ ano do Ensino Fundamental II e $3^{\circ}$ ano de Ensino Médio.

O presente trabalho é um recorte de uma pesquisa de doutorado que teve o projeto de trabalho juntamente com os questionários aprovados pelo Comitê Nacional de Ética em Pesquisa com Seres Humanos (número do processo: CAAE 02230512.0.1001.5148, e o parecer favorável de número 44936). Após esse trâmite, a pesquisa foi autorizada pela coordenadora da escola e os questionários foram aplicados.

\section{RESULTADOS E DISCUSSÃO}

Análise das respostas dadas pelos estudantes do Ensino Fundamental II, para a pergunta do questionário sobre "a frequência do uso de recursos audiovisuais pelos professores em suas aulas”, observamos que de acordo com esses estudantes, os professores, na maioria de suas aulas, não utilizam qualquer tipo de recurso audiovisual (Gráfico 1).

Segundo os estudantes, quando o professor utiliza algum recurso audiovisual limita-se à TV/DVD ou Datashow, e raramente faz uso do aparelho de som, do laboratório de informática e do retroprojetor.

Gráfico 1- Frequência da utilização dos recursos didáticos nas aulas de Ciências do Ensino Fundamental II.

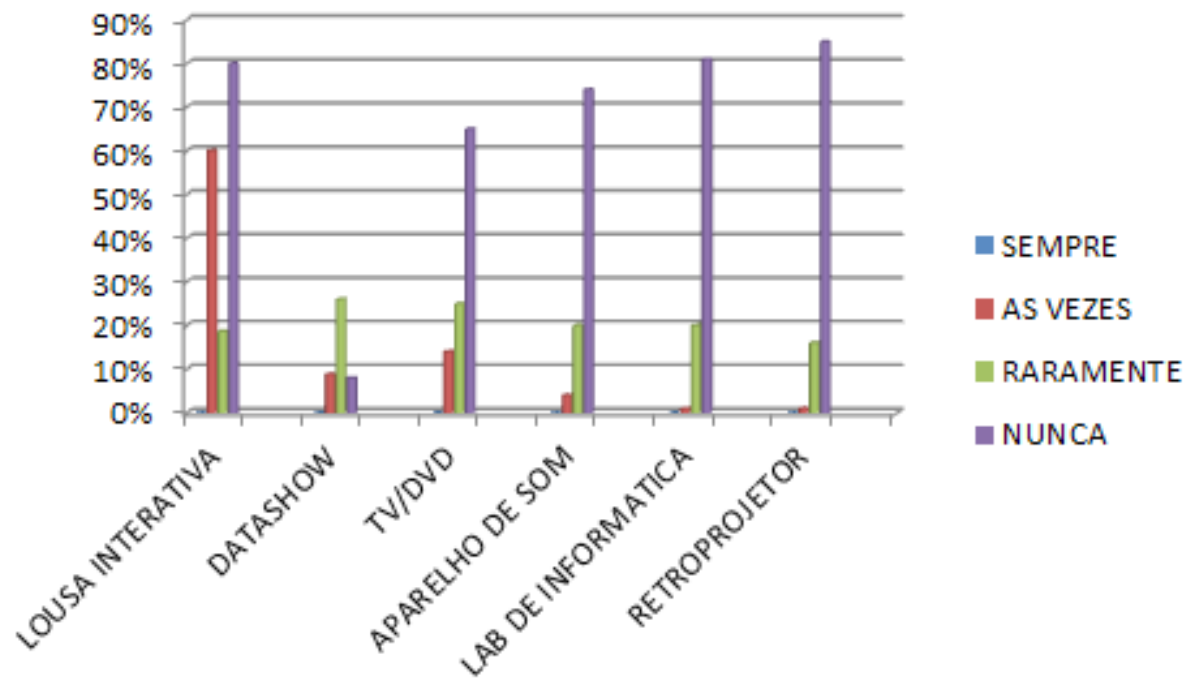

Fonte: dos autores. 
Percebemos ainda que vários estudantes não sabem o que é lousa interativa, pois muitos disseram que às vezes seus professores fazem o uso desta, em suas aulas, o que não é possível, porque a escola não dispõe de tal recurso.

Esta mesma pergunta "a frequência do uso de recursos audiovisuais pelos professores em suas aulas" foi feita aos estudantes do Ensino Médio, e as respostas foram mais distribuídas entre as opções apresentas aos estudantes (Gráfico 2). Porém os resultados são semelhantes, pois disseram que os recursos mais usados pelos os professores são Datashow, Lousa interativa e TV/DVD, alguns cometeram o mesmo equívoco cometido por alguns estudantes do Ensino Fundamental II ao afirmarem que às vezes ou raramente os professores utilizam a Lousa Interativa que não existe na escola.

\section{Gráfico 2 - Frequência da utilização dos recursos didáticos nas aulas de Biologia do Ensino Médio.}

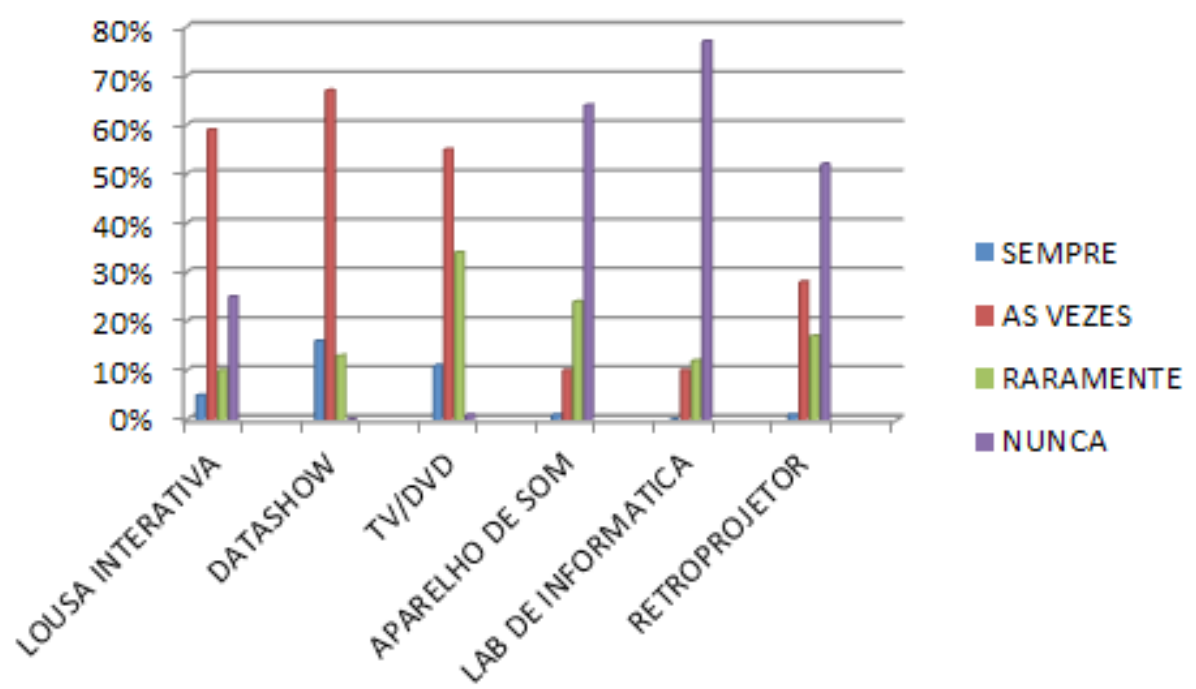

Fonte: dos autores.

Já sobre a preferência dos estudantes por determinados recursos didáticos, observamos que estes optam pelo uso de TV/DVD e Datashow (Gráficos 3 e 4), pois os mesmos possibilitam a apresentação e representação de estruturas e conceitos às vezes muito abstratos, auxiliando desta forma na relação ensino-aprendizagem. Nenhum estudante manifestou preferência pelo retroprojetor.

Os estudantes do Ensino Fundamental II se dividiram proporcionalmente entre TV/DVD e Datashow, enquanto os estudantes do Ensino Médio tem maior preferência pelo Datashow, depois pela TV/DVD. 
Gráfico 3 - Preferência dos recursos audiovisuais por estudantes do Ensino Fundamental II nas aulas de Ciências.

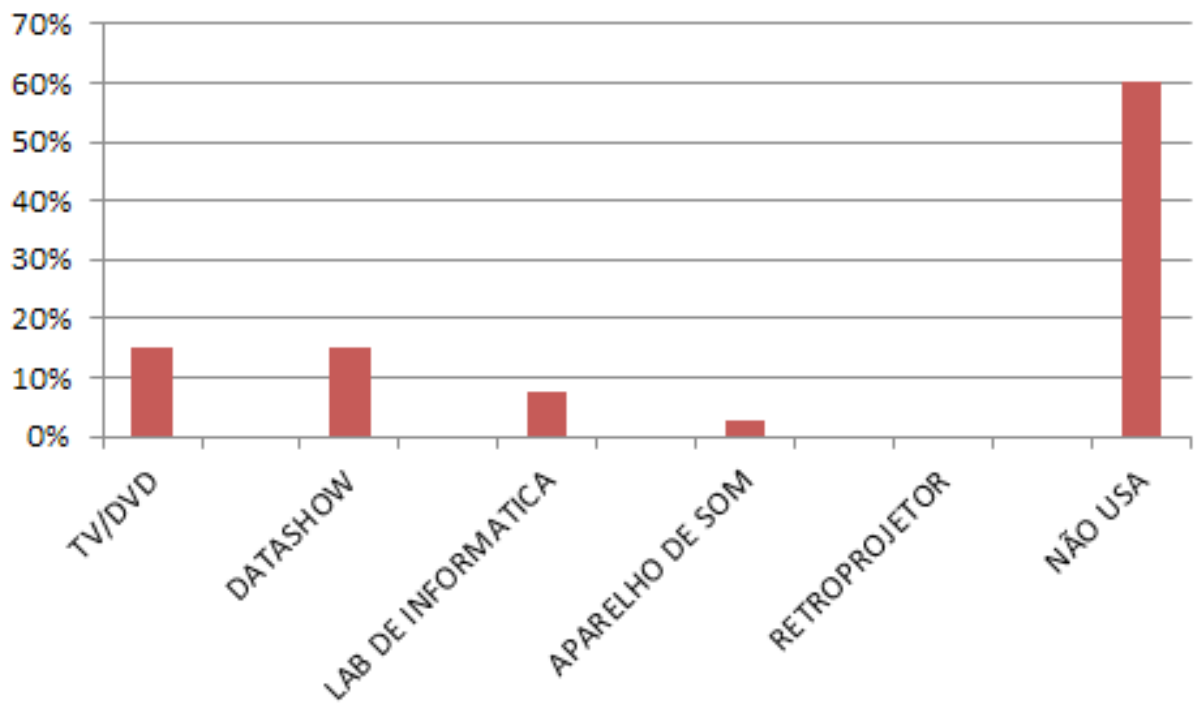

Fonte: dos autores.

O uso de Datashow permite uma projeção de alta resolução, que enfatiza as cores, belezas e detalhes das imagens. É visível de qualquer ponto da sala de aula. E, como as imagens em si não garantem nenhuma apreensão de conteúdos, devem ser sempre acompanhados de abordagens convenientes, de sensibilização do educando para o mundo natural. Proporciona, enfim, que o estudante se sinta um aprendiz naturalista e aventureiro, expansivo e aberto em aprender, pensar, questionar e, principalmente, querer saber mais (FERNANDES, 1998). O uso de imagens e textos deve complementar a explicação do professor tornando a ideia mais acessível.

A importância deste tema é bastante grande, uma vez que a sociedade moderna tem no uso da imagem e do som uma de suas principais características (ROSA, 2000).

Gráfico 4: Preferência dos recursos audiovisuais por estudantes do Ensino Médio nas aulas de Biologia.

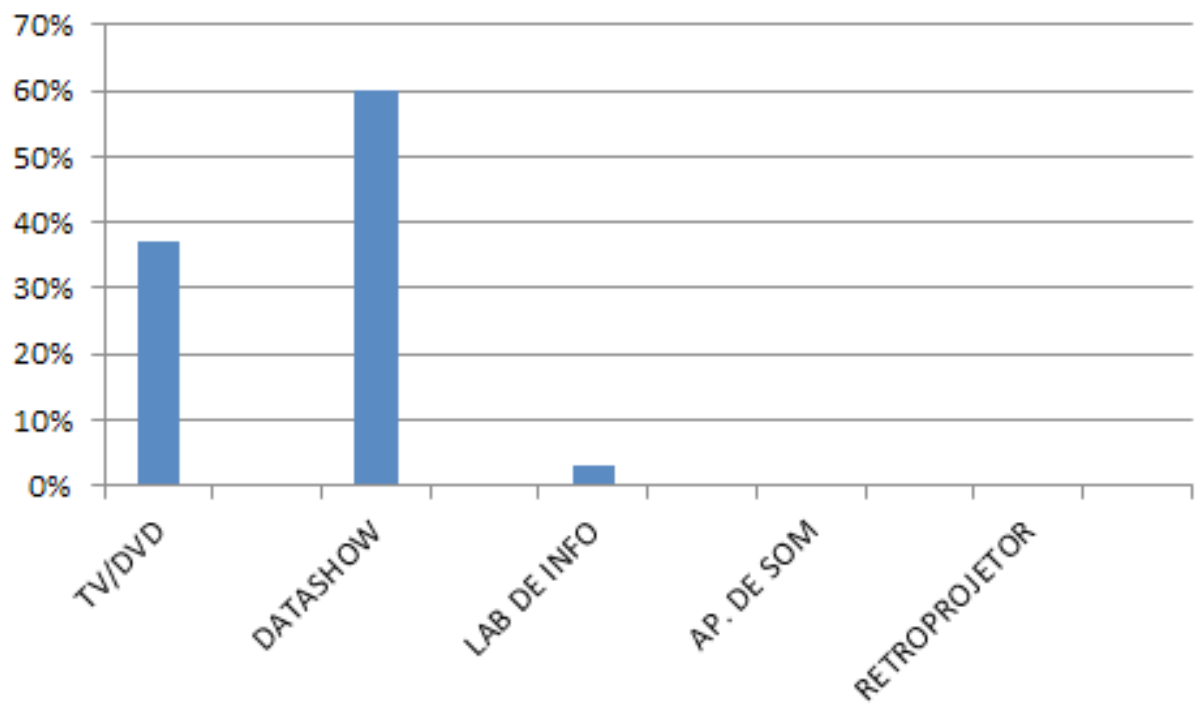

Fonte: dos autores. 
Perguntamos aos professores de Ciências e de Biologia quanto ao uso dos recursos audiovisuais disponíveis na escola como Datashow, TV/DVD (2 aparelhos de Datashow e 2 TV/DVD), Laboratório de Informática (Lab. Info) e Aparelho de Som (Ap. de Som), o que estaria impedindo o uso dos mesmos em suas aulas. Três professores responderam:

"muitos colegas acham que "perdem tempo" com a instalação dos equipamentos na sala de aula, pois na escola não tem uma sala apropriada para este fim”.

Um dos quatro professores que responderam ao questionário disse que muitos colegas ainda não tem domínio do uso de alguns recursos, e preferem trabalhar apenas com o livro, quadro e giz, sendo esses recursos ainda os mais usados, já que para uso dos mesmos não é preciso marcar data e hora e não tem perigo de quebrar ou queimar, o que é possível quando se está utilizando um Datashow.

Os professores alegaram que nunca tiveram qualquer tipo de treinamento para usar corretamente os recursos audiovisuais ou mesmo o laboratório de informática. Aqueles que tiveram interesse buscaram informações por conta própria.

Todos os professores pesquisados concordaram que a melhor estratégia para o ensino de Microbiologia do Solo no Ensino Fundamental II e Médio seria complementar e ilustrar o estudo através de filmes, vídeos/aulas, documentários ou animações explicativas do assunto que está sendo trabalhado durante as aulas. E ainda, disseram que, quando os recursos audiovisuais são usados de forma orientada e planejada com os estudantes podem ser ferramentas importantes para facilitar a compreensão dos conteúdos estudados.

Entre os conteúdos estudados é necessário que exista na estrutura cognitiva um ou mais conceitos nos quais o novo conceito se ligue de forma significativa. Quando este(s) conceito(s) não existe(m), uma alternativa é usar um material instrucional que estabeleça essa ponte conceitual entre o novo conceito e a estrutura cognitiva, chamado de organizador prévio. Um audiovisual é uma boa alternativa para ser usado como organizador prévio (AUSUBEL, 1969; MOREIRA, 1983).

De acordo com os estudantes pesquisados o uso de recursos audiovisuais pelo professor ajuda completar a matéria do livro de maneira mais explicativa. A maioria dos estudantes do Ensino Médio concorda que o uso de filmes, vídeo/ aulas, documentários ou animações explicativas facilitaria a aprendizagem do conteúdo de Microbiologia do Solo.

O uso de recursos audiovisuais aliados à orientação do professor pode ser significativo, na viabilidade de imprimir novas possibilidades de conhecimento (FRANCISCO et al., 2013). Para Diório e Rôças (2013), as mídias podem ser empregadas como ferramenta pedagógica e contribuir para ensino de Biologia e Ciências e, consequentemente, para a alfabetização científica.

Dentre as várias justificativas apresentadas pelos estudantes para o uso dos RA, escolhemos algumas como exemplos:

- Facilita o entendimento da matéria.

- Facilita a compreensão dos micro-organismos, pois são microscópios.

- As imagens trazem uma riqueza de detalhes.

- Passa bastante informações e é mais interessante.

- Aumenta o interesse do estudante pelo assunto.

- Aulas com assuntos do dia a dia.

- A aula não fica chata e cansativa.

- As aulas ficam mais chamativas. 
Estas justificativas apontam que os professores devem ficar atentos ao contexto social dos estudantes, bem como as questões científicas e tecnológicas, que passaram a ter grande influência no cotidiano da sociedade, por isso convive-se não só com os benefícios das novas tecnologias, mas também com todos os impactos causados por ela.

A linguagem audiovisual consegue chegar e ir além do que é percebido mediante imagens básicas, propiciando, dessa forma, outra possibilidade para a leitura de mundo. São capazes de provocar diferentes emoções e sensações (ARROIO; GIORDAN, 2006). O vídeo pode atuar no processo de ensino e aprendizagem não apenas como um auxílio, mas também como um elemento configurador da relação entre professor, estudante, conteúdos e objetivos, relação esta que pode se refletir nos processos cognitivos e atitudinais dos estudantes (MARCELINO JÚNIOR et al., 2004).

É perceptível que as informações visuais podem auxiliar nos processos educacionais, e hoje, a maioria dos jovens passa muito tempo em frente ao computador, visitando vários sites da internet, em casa, na escola ou em locais públicos (OLIVEIRA; JÚNIOR, 2012).

\section{CONSIDERAÇÕES FINAIS}

Os professores de Ciências e Biologia utilizam pouco os recursos audiovisuais disponíveis na escola. Os professores e direção da escola deveriam equipar salas próprias para o uso dos recursos audiovisuais, onde estes ficassem disponíveis para uso, evitando os contratempos de instalá-los nas salas de aula. Pois uma das justificativas dada pelos professores por não usá-los é a dificuldade para instalar os equipamentos assim "perdendo tempo" da aula que é limitado em 50 minutos.

Percebemos que os professores de Ciências e de Biologia tem preferência pelo o uso do Datashow e da TV/DVD. O número desses recursos na escola é limitado, o que pode causar mais dificuldades no uso dos mesmos, como dias disponíveis para agendamentos, desgastes dos equipamentos e falta de manutenção. Os outros recursos ficam obsoletos e danificados por falta de uso, como acontece com o laboratório de informática.

Este quadro leva-nos a pensar na qualidade e quantidade dos recursos audiovisuais disponíveis na escola pública e na formação dos professores para utilizarem tais recursos.

Os estudantes preferem aulas com uso de Datashow e veem nos recursos audiovisuais inúmeras possibilidades que podem ajudar no ensino de Microbiologia do Solo.

AGRADECIMENTOS: À FAPEMIG e CAPES - Edital FAPEMIG 13/2012 pesquisa em educação básica, acordo CAPES - FAPEMIG processo: CBB - APQ-03482-14 pelo financiamento do projeto e pela bolsa de R.C. Vilas Boas e ao CNPq, pela bolsa de produtividade em pesquisa de F.M.S. Moreira. 


\section{REFERÊNCIAS}

ARROIO, A.; GIORDAN, M. O vídeo educativo: aspectos da organização do ensino. Química Nova na Escola, n. 24, p. 8-11, 2006.

AUSUBEL, D. P.; Novak, J. D.; Hanesian, J. Psicologia educacional. Rio de Janeiro: Interamericana, 1980.

BRASIL. Plano Nacional de Educação para o decênio 2011-2020 (PNE - 2011/2020): Ensino Médio. Brasília: Ministério da Educação. Secretaria de Educação Média e Tecnológica. 2010.

DALLACOSTA, A.; TAROUCO, L. M. R.; FRANCO, S. R. K. Vídeos indexados: que benefícios trazem para o professor e para os estudantes. Novas tecnologias na Educação, Rio Grande do Sul, v. 5 n.1, p. 1-10, 2007.

DEV, P. \& WALKER, D. F. From virtual frog to frog island: design studies in a development project. Journal of Curriculum Studies. 1999. p. 635-659.

DIÓRIO, A. P. I.; RÔÇAS, G. As mídias como ferramenta pedagógica para o Ensino de Ciências: uma experiência na formação de professores de nível médio. Revista Práxis | ano V, nº 10, Dezembro de 2013.

FERNANDES, H.L. Um naturalista na sala de aula. Ciência \& Ensino, v. 5, n. 2, p. 50-57, 1998.

FRANCISCO, W.; FRANCISCO JUNIOR, W.E. Leitura e demonstração de experimentos por meio de vídeos: análise de uma proposta a partir da escrita dos estudantes. Revista Brasileira de Pesquisa em Educação em Ciências, v. 13, n. 1, p. 49-65, 2013.

GALEMBECK, E. (org.); TORRES, B. B.; ORSI, C. H.; FREITAS, D. R. C.; YOKAICHIYA, D. K.; SOARDI, F. S.; HORNINK, G. G.; PETERS, H. \& SFAIR, J. C. Manual do usuário: Biologia em multimeios, São Paulo: Kitmais, 2004.

LEHMAN, J. D. Biology education with interactive videodiscs 1. Fexibly using commercially available videodisc 1. American Biology Teacher, 1985. p. 34-37.

MARCELINO JÚNIOR, C. A. C.; BARBOSA, R. M. N.; CAMPOS, A. F.; LEÃO, M. B. C.; CUNHA, H. S.; PAVÃO, A. C. Perfumes e Essências: a utilização de um vídeo na abordagem das funções orgânicas. Química Nova na Escola, n. 19, p. 15-18, 2004.

MINAYO, M. C. S. O desafio do conhecimento: pesquisa qualitativa em saúde. 8 ed. São Paulo: Hucitec, 2004.

MOREIRA, M. A. Uma abordagem cognitivista ao ensino da Física. Porto Alegre: Editora da Universidade, 1983.

OLIVEIRA, N. M.; JÚNIOR, W. D. O uso do vídeo como ferramenta de ensino aplicada em Biologia celular ENCICLOPÉDIA BIOSFERA, Centro Científico Conhecer - Goiânia, v.8, n.14, p. 1788-1809, 2012.

PINHO, K.E.P. e LEPIENSKI, L.M. Recursos Didáticos no ensino de biologia e ciências [Online]. Disponível em: http://www.diadiaeducacao.pr.gov.br/portals/pde/arquivos/400-2.pdf?PHPSESSID=2009071511113042 Acesso em: 21 nov. 2013.

PEAT, M. \& A. FERNANDEZ. The Role of Information Technology in Biology Education: An Australian Perspective. J. Biol. Educ, 2000. p.69-73.

ROSA, P. R. S. O uso dos recursos audiovisuais e o ensino De ciências. Cad. Cat. Ens. Fís., v. 17, n. 1, p. 33-49, 2000.

SOUZA, D. C.; NASCIMENTO JUNIOR, A. F. Jogos didático-pedagógicos ecológicos: uma proposta para o ensino de ciências, ecologia e educação ambiental. In: Anais do V Encontro Nacional de Pesquisa em Educação em Ciências, 2005, p. 1-12. 


\section{ANEXO - QUESTIONÁRIOS APLICADOS: \\ QUESTIONÁRIO DOS ESTUDANTES - UTILIZAÇÃO DE RECURSOS AUDIOVISUAIS COMO ESTRATÉGIA DE ENSINO DE MICROBIOLOGIA NO ENSINO MÉDIO}

Prezado (a) aluno (a).

Este questionário faz parte da coleta de dados que fornecerá informações para direcionar a produção de um recurso áudio/visual, para complementar o ensino de Microbiologia do Solo, para estudantes do Ensino Fundamental II e Médio da rede pública Estadual de Minas Gerais. Obrigado pela colaboração.

Escola:

Nome: Série Data

Responda:

01-Com que frequência seu professor de Ciências ou de Biologia faz uso dos seguintes recursos áudio/ visuais em suas aulas?

Lousa interativa (vídeos, slides)
a) Sempre
b) Às vezes
c) Raramente
d) Nunca

Data show (vídeos, slides)
a) Sempre
b) Às vezes
c) Raramente
d) Nunca

TV/DVD (vídeos)
a) Sempre
b) Às vezes
c) Raramente
d) Nunca

Aparelho de som
a) Sempre
b) Às vezes
c) Raramente
d) Nunca

Computador (laboratório de informática)
a) Sempre
b) Às vezes
c) Raramente
d) Nunca

Retroprojetor
a) Sempre
b) Às vezes
c) Raramente
d) Nunca

Comentários:

02- Dentre os recursos audiovisuais utilizados pelo seu professor, qual você mais gosta?
a) TV/DVD
b) Datashow
c) Computador (internet)
d) Aparelhos de som

Comentários: 
03 - O uso de Recursos Audiovisuais, pelo seu professor, em atividades normalmente limita-se a:
a. Apenas um passatempo;
b. Muitas vezes, apresentação de conteúdos sem relação com a matéria que está sendo estudada;
c. Complementar de maneira explicativa a matéria do livro didático;
d. Forma de fazer uma aula diferente.

\section{Comentários:}

04- Dentre os recursos audiovisuais que podem ser utilizados pelo professor em suas aulas, qual em sua opinião facilitaria a aprendizagem do conteúdo de Microbiologia do Solo.

a. O uso de filmes, vídeos/aulas, documentários ou animações explicativas do assunto que está sendo estudado durante as aulas;

b. O uso de slides com ilustrações e esquemas que são explicados pelo professor;

c. O uso de paródias para decorar o conteúdo, facilitando no momento da prova;

d. O uso da TV/DVD para assistir vídeo/aulas gravadas pela TV escola, telecurso, PRÉ-ENEM e outros.

Justifique sua resposta:

\section{QUESTIONÁRIO DOS PROFESSORES - UTILIZAÇÃO DE RECURSOS AUDIOVISUAIS COMO ESTRATÉGIA DE ENSINO DE MICROBIOLOGIA NO ENSINO MÉDIO}

Prezado (a) professor (a).

Este questionário faz parte da coleta de dados que fornecerá informações para direcionar a produção de um recurso áudio/visual, para complementar o ensino de Microbiologia do Solo, para estudantes do Ensino Fundamental II e Médio da rede pública Estadual de Minas Gerais. Obrigado pela colaboração.

Escola:

Nome:

Data

Responda:

01 - Novas tecnologias têm sido disponibilizadas nas escolas públicas e visam diferenciar a forma de aquisição de conhecimentos. Quanto ao uso dessas inovações, pode-se afirmar que:

a. Muitos professores ainda não têm domínio do uso e preferem trabalhar apenas com o livro, quadro e giz;

b. Os aparelhos não recebem manutenção e não têm condições reais de uso; 
c. Professores não fazem uso, pois têm medo de danificar os aparelhos.

d. Professores acham que "perdem tempo" com a instalação dos equipamentos na sala de aula, pois na escola não tem uma sala apropriada para este fim.

\section{Comentários:}

02 - Os professores geralmente não fazem uso de recursos áudio/visuais (Datashow, TV/DVD, Sala de informática), porque:

a. Têm dificuldades para agendar com antecedência o dia e hora para usar;

b. Têm que apresentar um breve relatório sobre o que vai ser trabalhado (objetivo e coerência com o que está no planejamento), não dispondo de tempo para isso;

c. A maioria dos alunos não presta a atenção, conversa e brinca o tempo todo atrapalhando aqueles que desejam aprender;

d. A escola não possui um número adequado de aparelhos de TV, DVD, Datashow para o número de turmas formadas.

\section{Comentários:}

03 - Em algum momento durante o tempo que trabalha como professor na rede estadual de ensino de Minas Gerais você recebeu algum treinamento por parte do Estado para trabalhar com esses recursos didáticos: Lousa interativa, Datashow, software educativos.
( ) Sim
( ) Não
( ) Busquei informações por conta própria.

\section{Comentários:}

04 - Você concorda que os recursos áudio/visuais, quando usados de forma orientada e planejada com os alunos são ferramentas que podem facilitar a compreensão dos conteúdos estudados?
( ) Sim
( ) Não

\section{Comentários:}

05 Para o ensino de Microbiologia do Solo no Ensino Fundamental II e no Ensino Médio a melhor estratégia para complementar e ilustrar o estudo desse tema seria:

a. O uso de filmes, vídeos/aulas, documentários ou animações explicativas do assunto que está sendo estudado durante as aulas;

b. O uso de slides com ilustrações e esquemas que são explicados pelo professor;

c. O uso de paródias para decorar o conteúdo, facilitando no momento da prova;

d. O uso da TV/DVD para assistir vídeo/aulas gravadas pela TV escola, telecurso, PRÉ-ENEM e outros. 